\title{
Dispositions manifest themselves: an identity theory of properties
}

\section{Kristina Engelhard ${ }^{1}$ (D)}

Received: 5 November 2020 / Accepted: 26 August 2021 / Published online: 1 November 2021

(c) The Author(s) 2021

\begin{abstract}
The aim of this paper is to motivate a view on dispositions according to which dispositions and their manifestations are partially identical, the DM identity theory. It sets out by extrapolating the desiderata of a dispositionalist account of properties. It then shows that the previous theories are burdened with different problems, whose common cause, so the argument goes, is the separation assumption, which almost all share. It states that dispositions and their manifestations are numerically distinct. The paper then explores whether the separation assumption can be abandoned and shows that there are precursors of a DM identity theory. The DM identity theory is then outlined in its central features and it is outlined how they can fulfil the desiderata of dispositionalism.
\end{abstract}

Keywords Dispositions $\cdot$ Properties $\cdot$ Powers $\cdot$ Powerful qualities

In this paper, I will sketch a new theory proposal in broad outlines, which aims mainly at finding an architecture for the inner structure of dispositions. It is supposed to solve intrinsic theoretical problems of previous approaches of dispositionalism that have plagued the account for a while, without abandoning its advantages over its rival theories. The basic theses of my paper are, (1) that nearly all previous accounts of dispositionalism are based on an assumption, which I call the "separation thesis", (2) that this thesis is the cause of most of the intrinsic theoretical problems of dispositionalism, (3) that abandoning it might be an attractive option. The separation thesis says that non-manifest dispositions and their manifestations are distinct entities. If this thesis is abandoned, one assumes instead that non-manifest dispositions and their manifestations are not distinct entities, but that they are

\section{This article belongs to the topical collection "New Foundations of Dispositionalism", edited by} Andrea Raimondi and Lorenzo Azzano.

\section{Kristina Engelhard}

engelhard@uni-trier.de

1 Department of Philosophy, Trier University, Trier, Germany 
at least partially identical. One way to spell my thesis out is to say that when a disposition manifests it manifests its own self-sameness. ${ }^{1}$ Therefore I call this theory "D-M-identity-theory" (DMI henceforth).

In order to motivate my approach, I will first present the desiderata for a theory of dispositions, in order to show in part five that the DMI has resources to fulfil these desiderata. In the second part I will outline what I call the standard model of dispositions while showing in the third part that the standard model of dispositions is afflicted with four basic problems, dispositionalism has been accused of in recent years. In the fourth part I argue that the problems of the standard model have their origin in the separation-thesis. In the fifth part I will sketch a dispositional account that dispenses with the separation thesis- the DMI. I also show that first steps towards this approach have already been done in the literature. Finally, in the sixth part, I very briefly give a concluding outlook on some tasks that a fully fleshed out version of the approach would have to deal with.

\section{Desiderata for a dispositionalist theory of properties}

A dispositionalist theory of properties must ultimately prove itself by outperforming other theories of the same subject area-in particular concerning questions about natural modality, i.e. what is possible or necessary in accordance with laws of nature or causation-with respect to theory selection criteria, i.e. explanatory power, adequacy of the phenomena, plausibility, simplicity etc. But first of all, it must be shown that a dispositional theory can be coherent in the first place and informative. 'Informative' here means that a theory contains not too many stipulative assumptions; this is particularly important for those elements of the theory that carry much explicative weight. In dispositionalist theories this commonly applies to the (internal) structure of the properties. Hence, it is desirable that the (internal) structure is thus constituted that it is able to fulfil its explicative tasks. The most general desideratum for a theory of dispositions is therefore to develop a viable architecture for a model of the internal structure of dispositions which is supposed to be explicative for the following more specific desiderata. However in previous theories and approaches these desiderata are connected with unsolved problems:

- Identity of dispositional properties:

A theory of dispositional properties must include information about how it accounts for the identity of its dispositional properties. Since non-manifest dispositional properties are epistemically inaccessible most accounts fix their identity in their manifestations. An influential account is Bird's theory (Bird, 2007), according to which the identity of dispositions is fixed by their manifestations, so that dispositions constitute a network of properties mutually connected by a second order manifestation relation, or SR-relation, whereby the identity of a dispo-

\footnotetext{
1 I owe this formulation to one of the anonymous reviewers.
} 
sition is ultimately determined only by the relations in which it stands. ${ }^{2}$ This theory has come under serious attack (Barker, 2009; Barker \& Smart, 2012), which led to the emergence of a whole series of theories that attempt to avoid this difficulty; they reanimate and enhance the original identity theory of Martin and Heil (Martin \& Heil, 1999; Martin, 2008), the most important is the powerful qualities view (Jacobs, 2011; Ingthorsson, 2013; Taylor, 2018, 2019; Gianotti, 2019) and qualitative dispositional essentialism (Tugby, 2012).

Regardless of whether a pandispositionalism (the view that all properties are dispositions), a dispositional monism (the view that at least all fundamental properties are dispositions), or a weak dualism (which accepts categorical properties in its ontology in addition to dispositions, for example for mathematical or structural properties), the same problems arise with respect to the question of how the identity of dispositions is determined.

- Directedness: In most dispositionalist positions directedness is an essential characteristic of dispositional properties in contrast to categorical properties that do not have this second order characteristic. 'Directedness' means that a non-manifest disposition aims at a specific manifestation (Molnar, 2003, p. 60; Giannini, 2020). A dispositionalist theory should be able to explain what constitutes the directedness of a disposition.

- The connection between disposition and manifestation: A theory of dispositions should be able to explain the relation between a disposition and its manifestation, whether it is e.g. a sui generis manifestation relation or causation.

- Relation between dispositions and natural modality: A dispositionalist theory should explain how dispositions relate to natural modality, especially the modality expressed in laws of nature, since dispositionalism has one of its supposedly most important explanatory strengths in this respect. It should explain how regularities in nature can be grounded in dispositions. There are good reasons to doubt that the previous approaches of dispositionalism have succeeded in showing how dispositions can justify natural modality (Jaag, 2014).

These four desiderata and the problems of dispositionalism associated with them are intertwined. A disposition theory must make the inner structure of dispositional properties transparent, with the goal of either explaining-in any acceptable sense of 'explaining' — or even substantiating the modal force inherent in dispositions.

However, it is in no way clear which feature of the modal force of natural modality is to be explained in this way. I think that so far it has been overlooked that dispositionalism must aim at grounding a very specific feature of natural modality which is involved in laws of nature. Since a thorough investigation would go beyond the scope of this study, we can only formulate the following thesis: The predominant feature of natural modality to be explained is the specificity of a certain outcome behaviour when a dispositional property manifests, that the outcome behaviour has a precise quality. What we ask for when we ask why it is that electrical charge

\footnotetext{
2 "Dispositional monism is the view that all there is to (the identity of) any property is a matter of its second-order relations to other properties." (Bird, 2006, p. 217; cf. also Bird, 2007).
} 
necessarily brings about a behaviour according to Coulomb's law, is not why it is just at that moment of time that it comes about or whether there are no conditions that might prevent the outcome. In my view-the primary question is why is it that it is the behaviour according to Coulomb's law but not any other that electric charge brings about. I call this feature of natural modality "qualitative natural modality". So, it is qualitative natural modality which is primarily to be grounded in dispositional properties.

\section{The standard model of dispositions}

The standard model of dispositions can be illustrated by the simple conditional analysis of dispositions (SCA), which features dispositions (D), manifestation conditions $(\mathrm{MC})$, stimulus $(\mathrm{S})$ and manifestations $(\mathrm{M})^{3}$ :

$$
(\mathrm{SCA}) \mathrm{D}_{(\mathrm{S}, \mathrm{M})} \mathrm{x}:=\mathrm{MCx} \& \mathrm{Sx} \square \rightarrow \mathrm{Mx}
$$

Even if dispositionalists either consider the conditional analysis of dispositions as failed or as irrelevant, the standard model of dispositions in almost all previous dispositionalist approaches and theories assumes what seems to be established in the conditional analysis, namely that disposition and manifestation are numerically different or separate from each other. Almost all dispositionalist theories share a thesis, which I call the assumption of separation (AS):

(AS) D and M are separate, numerically different entities.

Here $\mathrm{D}$ and $\mathrm{M}$ are properties, powers, characteristics of powers. Some dispositionalists think that $\mathrm{D}$ and $\mathrm{M}$ can also belong to different categories; Mumford/ Anjum assume that dispositions are properties associated with powers and manifestations are effects that can also be understood as events (Mumford \& Anjum, 2011, p. 6).

That the assumption of separation is a basic prerequisite of dispositionalism has been clearly formulated by Mumford:

There are two further significant features in the characterization of powers. These mark the powers ontology clearly as anti-Humean. First, each power is essentially, or necessarily related to manifestations of a specific kind. Hence, solubility is essentially related to dissolving; fragility is essentially related to breaking. Second, however, the power and its manifestation are distinct existences. The power can exist without being manifested, if it is not stimulated for instance. When these two features are combined, they have the clear result that there can be necessary connections between distinct existences - in direct contradiction to Humeanism. (Mumford, 2009b, 269f.)

According to Mumford, the separation of powers and their manifestations is a central assumption of dispositionalism; it is one of the assumptions that is involved in the

${ }^{3}$ Cf. Bird (2007). 
clear demarcation between Humeanism and dispositionalism. Humeanism argues that there are no necessary connections between distinct existences, while dispositionalism denies this. Both however seem to share the view that natural modality, connected with causation or laws of nature ultimately grounds in some necessary connection, which can only be assumed to hold between distinct existences.

My first question for the following part is now: Is the assumption of separation nevertheless a vital source of central problems of dispositionalism? If this is so, then the question must be asked: Can the assumption of separation be abandoned at all? Is it a viable alternative for dispositionalism to assume that a disposition is not separate and numerically different from its manifestation, but that they are one and the same thing?

The theses of the following parts are, first, that the D-M standard model of dispositions burdens dispositionalism with problems and ambiguities central to its theory. Secondly, I want to show that there is an alternative, the D-M identity theory (DMI), and thirdly, that the DMI does not pose these problems and provides better proposals for the explication of dispositionalism. The D-M standard model is not misguided, but it reflects only the phenomenal surface structure of properties and their causalnomological profiles, it is a relic of Humeanism in general and its theory of causation more precisely.

\section{The standard model and its problems}

Dispositionalism could claim an important explanatory power for itself if it could fulfil its project of grounding natural modality. Many dispositionalists share this assessment and believe that this project has been successfully completed:

There is interest in the power's metaphysics because powers can explain a broad range of issues in metaphysics, not just causation. Properties [...], causes, modality [...], events, and perhaps even particulars can all be explained in terms of powers. (Mumford \& Anjum, 2011)

Vetter even thinks that it is the central concern of dispositionalism to ground modality:

Dispositionalism is the view that the truth or falsity of modal statements is a matter of the dispositions that are present or instantiated in the actual world. Many dispositionalists speak in terms of truthmakers: thus they will say that modal truths are made true by the dispositions that are present or instantiated in the actual world. (Vetter, 2016, p. 2681)

Concerning this grounding project there are two paths in the literature: one takes the modality in dispositions to be a fundamental not further explicable fact, the other holds that it has to be provided by the internal structure of dispositional properties somehow. One of the most differentiated theories of the internal structure of dispositional properties is Bird's dispositional essentialism. Bird is especially concerned with the natural modality as expressed in the laws of nature: 
According to this picture, properties have relationships between them, that are essential to the natures of those properties. Laws just drop out as consequences of those relationships. (Bird, 2011)

So according to Bird it belongs to the essence of a property, that it stands in certain relations to others. These relations ground the laws of nature and also their modal force.

Nevertheless, there is good reason to doubt that dispositionalism has so far succeeded in providing a model that provides this justification.

A central critique has been elaborated by Jaag (2014). His thesis is that the currently best theory of dispositionalism is dispositional essentialism, but that its central thesis is incompatible with its claim to ground natural modality. The central assumption of dispositionalism is that the identity of a disposition D is determined by showing manifestation $\mathrm{M}$ given the manifestation condition $\mathrm{MC}$ and stimulus condition $\mathrm{S}$. Thus it is necessary that if $\mathrm{x}$ instantiates the dispositional property $\mathrm{P}$, then $\mathrm{x}$ has the disposition to $\mathrm{M}$ given the stimulus condition $\mathrm{S}$ (Bird, 2007, p. 45). Therefore, in dispositionalism a property is necessarily linked to a specific causalnomological profile. This means that properties with a dispositional essence are necessarily linked to a specific behaviour of objects. The property 'being electrically charged', E, for example, is connected with a particular behaviour of objects corresponding to Maxwell's equations and Coulomb's law, in all possible worlds in which $\mathrm{E}$ is instantiated. However, as Jaag shows, in Bird's account the problem arises that no satisfying explanation has been given for how the natural modality should emerge from something that itself does not already contain any modal feature: "It is unclear how certain (essential facts about) properties not including natural modalities translate into naturally modal facts about their instances. (Jaag, 2014, p. 16).

Barker and Smart have earlier criticized dispositionalism, particularly in the versions of Bird (2007), Mumford and Anjum (2011), for its attempt of providing natural modality (Barker \& Smart, 2012). Their thesis is that this dispositionalism does not differ significantly from Armstrong's necessitarianism in terms of the justification of laws of nature and that it is burdened with the same difficulties, namely the inference problem. Armstrong's N-relation and Bird's manifestation relation (SR) fulfil in the same way the function of grounding laws of nature:

What's significant is that both $\mathrm{N}$ and SR play the governing role, and that's where the problem comes from. It's the governing role that causes the regress (Barker \& Smart, 2012)

Bird assumes-unlike Armstrong - that it is essential for a property F to stand in the SR-relation to $G$, but it is not further explicable, why it is just $G$, which stands in the SR-relation to F and not $\mathrm{H}^{4}$ So it is a fundamental fact, that SR (F, G) is valid. So the SR-relation is fundamental too. Thus, Barker and Smart can rightly say that SR-relations actually play the governing role in relation to the properties themselves. The existence of the specific SR-relations between dispositional properties is

\footnotetext{
${ }^{4}$ In Armstrong very explicitely $\mathrm{N}(\mathrm{F}, \mathrm{G})$ is a contingent fact.
} 
therefore in the end as much a mere modal fact as the existence of the fact $\mathrm{N}(\mathrm{F}, \mathrm{G})$ in Armstrong. Even a regress looms. ${ }^{5}$ Thus, a satisfying grounding of natural modality is not achieved either.

Tugby has defended dispositionalism against this criticism by suggesting an approach similar to the powerful qualities view. ${ }^{6}$ This approach, unlike the powerful qualities view, is essentially dualistic. Tugby identifies as the source of Bird's problem diagnosed by Barker and Smart the monistic thesis that all fundamental properties are dispositional properties and that the nature of properties is completely filled by their second-order modal relations that fix their dispositional roles (Tugby, 2012, p. 723).

I think the lesson to be learnt at this point is that if a dispositional essentialist about properties is to avoid the regress problem in a way that is not also available to Armstrong, she needs to avoid giving a governing role to second-order (SR) relations. That is, she needs to explain the first-order behavioural regularities in a way that avoids appealing to governing second-order relational facts. This can indeed be achieved, I will argue, by removing the monistic aspect of the Bird-type view. (Tugby, 2012, p. 725)

According to his diagnosis, Tugby proposes a dualism in the form of a theory of powerful qualities, which he calls qualitative dispositional essentialism (QDE). According to QDE, qualities are characterized by a qualitative nature that is essentially linked to certain dispositions. In contrast to the theories of powerful qualities, the qualitative nature of a property is not identical with the dispositions, rather the qualitative nature of a property and the dispositions associated with it are different, so that the qualitative nature "confers" dispositions:

properties do have a qualitative nature, which is such as to essentially confer certain dispositions upon their possessors. [...] The qualities of things would therefore play the governing role [...] rather than the SR-relations. (Tugby, 2012, p. 727)

It is not quite clear in Tugby whether the dispositions, bestowed by the qualitative nature and the qualitative nature itself are two distinct moments of one and the same property, or whether the dispositions of the property, whose qualitative nature is essentially connected to the disposition, are to constitute a different property. But it is clear that this conception is to be understood explicitly in such a way that the qualitative nature of a property should replace Bird's SR-relation:

QDE schema: where $\mathrm{P}$ is any natural property, necessarily, if $\mathrm{x}$ has $\mathrm{P}$, then, in virtue of $x$ 's being $P$, if $x$ were $F$, then $x$ would be $G$ (ceteris paribus). (Tugby, 2012, p. 728)

\footnotetext{
5 The details are irrelevant in for my discussion: cf. Barker and Smart (2012, pp. 720-721).

${ }^{6}$ A very helpful distinction between the different types of dispositionalist identity theories can be found in Gianotti (2019).
} 
According to this scheme, qualities are essentially dispositional. The idea here is that it depends on the qualities of objects what objects can do. For example, if a disk has the property of being cogged at its outer edge, then, if it also has the property of being connected to an axis, it can move other suitably shaped objects, if it moves and the suitably shaped objects are brought into contact with the disk in the correct way. So: Being cogged gives the disk the disposition to move suitably shaped objects.

However, Tugby's solution strategy for the regress problem of Barker and Smart can also be understood differently: to ground the relationality of dispositional properties in one entity in order to avoid the problems of dispositionalism resulting from the separation thesis. From my point of view this strategy is the most promising, but I think that Tugby's solution using the QDE scheme is ultimately not successful in explaining or only showing how modal facts in nature emerge from the qualitative nature of a property. First of all, unlike Bird, Tugby can explain that there are different properties and different dispositions, namely that they are based on different qualities; but he cannot explain why a certain qualitative nature, let's call it $\mathrm{Q}$, is essentially linked to a specific disposition, let's call it D. The essential link between $\mathrm{Q}$ and D is assumed by means of stipulation. But there is nothing that explains why D is essentially connected with Q, but not with say R. Secondly, this stipulative essentialist assumption is intended to explain and justify the natural modality in first-order behavioural regularities. But the dispositions themselves do not explain them, in addition the manifestations are needed, which constitute the first-order behaviour. In order to explain and substantiate the first-order behavioural regularities, it is therefore not sufficient to substantiate the dispositions in qualities. It is necessary to explain how the specific behaviours of objects depend on their qualities. ${ }^{7}$

For dispositionalism, this means that it must either significantly weaken or abandon its claim to ground natural modality, or it must show exactly how in its model modal facts emerge from non-modal facts.

A second problem at least of dispositional monism is that it has to determine the identity of dispositional properties relationally:

Dispositional monism is the view that all there is to (the identity of) any property is a matter of its second-order relations to other properties. [...] the second order relation in question is the relation that holds, in virtue of a property's essence, between that property and its manifestation property-which we will call the manifestation-relation. (Bird 2007a, p. 139)

The identity of the property $\mathrm{F}$ consists in the fact that it is its essence, that it stands in the manifestation relation to the property G. But since the identity of the property $\mathrm{G}$ itself consists of being in manifestation relation to another property, it follows that all fundamental properties are embedded in a pattern of manifestation relations, which is supposed to confer to them their identity, so that the identity of the properties supervenes on the pattern of manifestation relations. ${ }^{8}$ Mumford also assumes

\footnotetext{
7 Jaag has further points of criticism about Tugby's QDE approach (Jaag, 2014, p. 17f.).

8 "Can the identity of potencies supervene on the pattern of their manifestation relations? The answer is that it can.” (Bird, 2007, p. 146).
} 
that all properties "form an interconnected web" (Mumford, 2004, p. 182), so that the identities of the properties supervene on the relations: "each property has an essence and identity only in relation to the other properties." (Mumford, 2004, p. 184). This leads to the objection: does dispositional monism of this type not structurally resemble or coincide with a form of ontic structural realism (OSR) and is burdened with similar problems? It would then no longer be possible to recognize the explanatory power of the concept of dispositional properties itself.

There is an additional problem for directedness, which is that the two relata have a different modal status: the disposition, the first relatum, is actually instantiated, while the manifestation, the second relatum, is only possibly instantiated. Psillos criticizes dispositional monism from the assumption that directedness is a dispositional property and shows that a regress is imminent: If directedness $Q$ is a dispositional property, the property $\mathrm{F}$ say, then it is directed to a manifestation, i.e. it is the power to $\phi$ (Psillos, 2006). Psillos' argument expressed in a truncated way is that if $\mathrm{Q}$ is a distinct power besides $\mathrm{F}$, then $\mathrm{Q}$ needs to have an own manifestation, which fixes its identity, G. But if Q itself is a power, which is directed to a manifestation $\mathrm{G}$, then it needs to have a directedness $\mathrm{R}$ to be directed to a manifestation of its own again, etc. ad infinitum.

Bauer has proposed a solution to the regress problem of directedness. According to his analysis, the problem arises from the assumption, that a disposition $\mathrm{F}$ and its directedness $\mathrm{Q}$ are two different dispositions. But the dispositionalist does not have to assume this; rather, as Bauer points out, dispositionalism is characterized by the assumption, that a disposition is just that directionality towards a manifestation $\mathrm{M}$ :

The Powers Regress Argument hinges on the premise that directionality, Q, is an essential but distinct disposition (and hence a distinct property) of any supposedly pure disposition, $\mathrm{F}$. In response, I claim that $\mathrm{Q}$ is not a distinct property apart from F. (Bauer, 2010, p. 43) It is not the case that $F$ has the power to bring about a manifestation, $\mathrm{M}$, or possesses directedness towards bringing about $\mathrm{M}$; rather, it is the case that $\mathrm{F}$ just is the power to bring about $\mathrm{M}$, or is directedness towards M. (Bauer, 2010, p. 46)

Bauer argues that dispositions are identical with being directed to their specific manifestations ${ }^{9}$ :

Thus, (1): it is not the case that $\mathrm{F}$ and $\mathrm{Q}$ are distinct properties. (Bauer, 2010, p. 45$)^{10}$

Bauer does not make clear, whether directedness $Q$ includes manifestation $M$ in any way, as indicated in the formulation "directedness towards bringing about $\mathrm{M}$ " or

\footnotetext{
${ }^{9}$ Marmodoro makes the same point under recourse to Aristotle: "But what we now realise is that a pure power does not have directionality as a property; a pure power $i s$ this or that instance of directionality towards $\varphi$-ing. That is what a pure power does when unmanifested; it is an instance of readiness for action, of pure directedness towards $\varphi$-ing, and only that. No division, no regress. Anything that possesses such a power $\mathrm{F}$, possesses directedness towards $\varphi$-ing, and so is disposed to $\varphi$." (Marmodoro, 2010).

${ }^{10}$ Cf. also Bauer (2010, p. 46; p. 48).
} 
"directedness towards M", or whether Q and $\mathrm{M}$ shall be understood as distinct properties. ${ }^{11}$ But since the standard model assumes the numerical difference between dispositions and their manifestations and Bauer does not explicitly reject this assumption, it can be assumed that he understands $\mathrm{Q}$ and $\mathrm{M}$ as distinct properties.

Unfortunately, Bauer did not elaborate further on his proposal, and so it remains unclear how exactly he understands the identity and also whether it should help to achieve further explanatory goals. What Bauer achieves with his approach is, similar to the basic intention of Tugby, to establish natural modality in first-order facts. Tugby establishes it in the qualitative nature of properties, Bauer in the directionality of dispositional characteristics, in which these are merged. Thus both avoid the problem that Barker and Smart saw in Bird's SR-relations, namely that a second order relation controls what happens in first order nature, facts, processes and events.

Bauer's proposed solution for the specific problem of directedness, which Psillos pointed out, is interesting because, according to my thesis, it follows the correct solution strategy, which is applicable to a whole group of structural problems of dispositionalism, namely to integrate a complex structure into a single entity. Dispositional properties are bound to a complex structure, but the question is how this complex structure must be modeled in order for the basic idea of dispositionalism to reach its explanatory goals consistently and coherently.

There are different options for integrating the complex dispositional structure into a single entity. One option is to understand Bird's SR-relation or the directedness relation as an internal relation. That dispositions are relationally individuated is often noticed by dispositionalists, but the possibility to model the manifestation relation or directedness as internal relations is hardly ever considered. Heil, however, openly posits the thesis that causality itself is an internal relation or can be traced back to an internal relation that characterizes dispositional properties:

You might or might not like the idea of explicating causal relations in terms of the manifestings of reciprocal powers. Let me suggest, however, that one attractive feature of such a view is that it enables us to understand truthmakers for causal claims of the form A caused B as non-relational features of the universe. This, in effect, makes causal relations internal relations. And that, I think, is a good thing. (Heil, 2016, p. 137. Also cf. Heil, 2012, pp. 135-150, esp. 148)

Heil takes this view because he considers a metaphysics of external relations to be unconvincing, but not because he wants to avoid problems of dispositionalism. Barker is of the opinion that the SR-relation is an internal relation, but in his view this does not solve the above discussed problem of avoiding the need to determine the SR -relation as a categorical property. To understand the SR-relation as an

\footnotetext{
11 Elsewhere, however, what a disposition is aimed at is modally qualified: „To be a disposition is to be a property directed towards some possible manifestation."(Bauer, 2010, p. 46). As with Molnar and others who hold directedness to be a central feature of the dispositional, perhaps here is the idea that directedness shares with mental intentionality the property that the manifestation to which a disposition is directed need not exist, and yet directedness can exist (Molnar, 2003, p. 63f.).
} 
internal relation would only solve the problem, if its internality would be an ontological free lunch, i.e. would not cause additional ontological costs beyond the powers, whose relation it should be. But Barker shows convincingly that this cannot be the case (Barker, 2009). In a nutshell, his argument can be expressed as that the SRrelation in Bird is constitutive of the identity of the properties. Indeed it is a second order property, but it is not derivative in relation to the powers. Thus the SR-relation is an internal relation according to some definitions of internality, but it is not an ontological free lunch.

I will try to show in the next section that these negative evaluations of dispositionalism are incorrect and that it is possible to defend an alternative approach.

\section{The separation thesis of the standard model of dispositions}

According to my diagnosis, an important source for the structural problems of the current approaches to dispositionalism is that it is forced to understand the relation between a disposition and its manifestation as a relation between numerically different entities. Therefore, it has to recognize a relation as fundamental and the modality to be explained by dispositionalism has to be anchored in this relation, so that natural modality is grounded in a fundamental relation and not in the dispositions that are the first relatum of the relation.

First of all, I would like to show that my diagnosis of the problem aims in a similar direction as that of other participants in the debate and that my solution strategy also has similarities with others that start from a similar diagnosis.

In their criticism of Bird's in particular, but also of Mumford/Anjum's dispositionalisms, Barker and Smart arrive at a similar diagnosis with regard to dispositional monism (Barker \& Smart, 2012). ${ }^{12}$ Their thesis is that, like DTA theory, it is burdened with the inference problem, i.e., with the problem of how the existence of the second-order SR-relation can de facto determine the existence of first-order facts. For Armstrong's version of the DTA theory, Bird had seen here a vital regress, which arises from legitimizing the conclusion from (1) $N(F, G)$ to (2) $\forall x(F x \rightarrow G x)$ by assuming that between (1) and (2) there is an enforcing relation legitimizing this conclusion: $\mathrm{N}^{*}((1),(2))$. $\mathrm{N}^{*}$ is a relation of third order. Now the problem is that $\mathrm{N}^{*}$ takes over the explanatory function, which originally $\mathrm{N}$ should do by itself: $\mathrm{N}$ was supposed to explain that there are regularities in nature; now $\mathrm{N}^{*}$ has taken over this explanatory function. But it is not recognizable, in how far $\mathrm{N}^{*}$ can do this explanation, so that again an explanatory relation of higher order must be assumed, and so on (see Bird 2005, p. 151). Barker and Smart show, that the same problem is present in Bird: The SR-relation between $\mathrm{D}$ and $\mathrm{M}$ given $\mathrm{S}$ must explain, that the instantiation of a disposition $\mathrm{D}$ requires a certain behaviour $\mathrm{M}$, if the stimulus condition is met. Thus, the same structure is present as with Armstrong: (1) SR ((D, M), S) does

\footnotetext{
12 I take Barker and Smart (2012) as critical representatives of the view; among others are Engelhard (2010), Ingthorsson (2015), Livanios (2017), pp. 31-54; Taylor (2018).
} 
not explain for itself that (2) $\forall \mathrm{x}$ (Dx \& Sx $\rightarrow \mathrm{Mx}$ ) applies. A further relation SR* must be assumed, which explains the relation of (1) and (2).

Barker and Smart's critique boils down to the fact that Bird's dispositionalism is not fundamentally different from DTA theory and thus the claim of dispositional essentialism to establish natural modality in the essence of properties is not fulfilled. Thus also a basic assumption of dispositionalism remains unexplained, that properties are necessarily linked to a causal-nomological profile. There is no way to see what kind of link this is. Barker and Smart argue that dispositional monism is forced to recognize "necessary connections between what exists separately" and they seem to suggest that the assumption of modal connections between what exists separately does not correspond to the basic intention of dispositionalism.

The ambition of dispositionalism should be to establish natural modality in firstorder facts, i.e. by instances of properties. It has to explain, why the instance of a dispositional property $\mathrm{P}$ forces a specific behaviour $\mathrm{B}$ in nature or makes it necessary or conditionally necessary. It cannot be contingent that $\mathrm{P}$ is linked with $\mathrm{B}$ instead of with another behaviour, e.g. C or D. In the DM standard model of dispositions, this linkage is always grounded by assuming that it lies in the essence, nature or quality of $\mathrm{P}$ that it is linked with $\mathrm{B}$. However, this can only be assumed stipulatively. That it is in the essence, nature or quality of $\mathrm{P}$ to enforce $\mathrm{B}$, to make it necessary or conditionally necessary, is a fundamental fact. Dispositionalism would better fulfil its claim to establish natural modality if it could do without the stipulation of such a modal fact.

I think it is plausible, after the previous discussion, that the separation thesis leads to problems for dispositionalism, so that it is worthwhile to find out whether it can be abandoned and whether the problems listed above can be solved with it. Is it possible to abandon the separation thesis and thus assume that dispositions are somehow identical with their manifestation? The question, why $\mathrm{P}$ is manifested in $\mathrm{B}$ and not in $\mathrm{C}$ or $\mathrm{D}$, would then no longer arise. And that $\mathrm{P}$ is manifested in $\mathrm{B}$ is then not a stipulated fact. But can a DMI be meaningfully constructed?

\section{The D-M identity theory}

\subsection{A precursor of DMI}

First of all, I would like to show that there is - at least according to a currently much discussed interpretation - an approach that starts from the identity of forces and their manifestations, this is the dynamis theory of Aristotle according to the interpretation of Marmodoro:

For Aristotle a power in potentiality is the same power as that power in actuality (i.e., when it is activated). In other words, the difference between potential and actual power is not a numerical difference. [...] the transition a power makes from being in potentiality to being in actuality does not amount to bringing about another power in potentiality. It is rather a transition the power makes to its own activated state. An activated power is the very same power as 
the power in potentiality, but is now manifesting [...]. It follows that Aristotle's ontology is not relational; a power is not defined in terms of its relation to other powers. Rather, a power is defined in terms of its own state of activation, which is an intrinsic state of the power itself. (Marmodoro, 2014, p. 19f.) ${ }^{13}$

According to Marmodoro, Aristotle conceived of powers in such a way that they could be in two states, an inactive and an active state. The manifestation of a power is the transition from one state to the other. The manifestation of the power is not the final state of the manifestation process, but either the activity of the power or the manifestation process.

Marmodoro interprets the activation of a power in Aristotle's work as being very similar to the mutual manifestation partner theory: "Hence, every power is dependent on other powers for actualizing its nature by reaching its full activation state. (Marmodoro, 2014, p. 22). In Aristotle's work, it is important that powers form a complementary pair of active and passive power: heat is the active power that requires a complementary power for its manifestation, namely the ability to be heated so that it can manifest its power to heat. Every power has a complement. According to Marmodoro, the modality that Aristotle derived from the nature of powers is natural necessity. It refers to the manifestation of a power that necessarily occurs under certain conditions, boundary conditions and spatial contact with a suitable complementary power. Natural necessity is not a strict necessity, but conditional necessity; for Aristotle believes that the manifestation of a power can be prevented by disruptive factors. As with the manifestation partner theories, in Aristotle's interpretation, causality consists in the fact that a power, together with all the conditions of its manifestation, is the cause of an effect. ${ }^{14}$

Yates has criticized this approach (Yates, 2016). His primary point is that there are fundamental physical properties that are clearly counterexamples; Yates' argument, however, is more aimed at a possible follow-up assumption to the identity thesis, namely that such powers are self-sufficient, i.e. ontologically independent of other powers. It is not entirely clear what Yates means by self-sufficiency here; it seems that he thinks that DMI must assume that observable behaviour is the sole manifestation of a power. The trigger must then only be understood as an external trigger of manifestation and not as a contributory cause. Yates' argument against DMI is therefore that electric charge is an example of a fundamental force, whose manifestation is not ontologically independent, but rather charge is dependent on mass in its manifestation:

\footnotetext{
13 My point here is not so much, whether Aristotle really held this position, but rather that it is at least an option to understand Aristotle that way (Marmodoro justifies her interpretation in Marmodoro, 2014, p. 4). I will only refer to those parts of Marmodoro's interpretation of Aristotle that I believe are relevant to a contemporary theory. Aristotle also distinguishes between active and passive powers; by passive powers, according to Marmodoro, he understands the ability to undergo change, to be warmable, for example. From today's perspective, this distinction is problematic because it plays no role, at least not in modern physics. Aristotle, on the other hand, uses it to explain how a latent force becomes manifest: when an active force comes into spatial contact with a matching passive power, they manifest.

14 Only recently Livanios has brought up a very close idea (2020); Giannini also tries to solve dispositionalist problems with Aristotelian means (Giannini, 2020).
} 
If charge is the power to exert forces on other charges, where the exertion of such a force is charge in its activated state, and force derives its identity (at least partially) from the acceleration it produces per unit mass, then charge in its activated state ontologically depends upon mass. [...] This dependency suggests that the manifestation of charge cannot be an activated state of charge itself. It is far more plausible to hold that mass, charge, and force are distinct reciprocal partner powers among whose mutual manifestation types are accelerations. There is simply nothing we can plausibly identify as the self-contained manifestation type of each partner power, when taken individually. (Yates, 2016, p. 146 f.)

DMI has several options here to overcome this objection. Firstly, Marmodoro firmly maintains that Aristotle advocates the mutual manifestation partner theory. At least in Aristotle's interpretation of Marmodoro, the DMI seems to be compatible with the mutual manifestation partner theory. Correctly understood in this theory, the manifestation of a single power is its contribution to an overall manifestation of all the powers involved. The self-sufficiency of the force is not necessary for the account. What remains of Yates' criticism is a general objection to a follow-up assumption of the mutual manifestation partner theory, the contribution theory, according to which the manifestations of powers are contributions to overall effects. Yates' criticism then says that the contribution theory leads to a situation where it becomes completely unclear how powers can be individuated, since the manifestations only figure as part of an overall effect and are no longer epistemically accessible as such:

There is simply nothing we can plausibly identify as the self-contained manifestation type of each partner power, when taken individually. (Yates, 2016, p. 147)

The argument of the mutual manifestation partner theory at this point is that one of the aims of science is to find out what contribution a power makes by screening off the influence of other powers under laboratory conditions (Mumford, 2009a, 104 with reference to Cartwright 1999 Chapter 4). For example, charge may be dependent on mass for its manifestation, but there is sufficient scientific reason to regard electric charge as a numerically distinct property of mass. A very similar account has extensively been spelled out by Corry (2019). It is one question how to isolate properties or powers in nature, and another question how these powers should be conceived metaphysically. To answer the first question can be understood as a matter of the empirical sciences.

So what is the structure of dispositional properties according to DMI? The basic idea of dispositions and powers according to DMI is that they have two states, a latency state and a manifest state or manifestation state. When a disposition becomes manifest, it is precisely that property that becomes manifest. Different from the standard model, the idea is not that two numerically different properties, two distinct existences, are linked, so that the manifestation of a disposition consists exclusively of a change of properties-like change or causal processes 
that accompany change are generally conceived-but that it is exactly that disposition that manifests itself.

\subsection{States of properties}

In this section I want to explain and make plausible the idea that dispositional properties are connected to states. McKitrick distinguishes dormant powers from active powers; however, she does not explain in more detail what status the distinction active/dormant has, whether it is a matter of states, modes, or the like:

The distinction between an active and dormant power is simply this: an active power is currently manifesting, whereas a dormant power is not currently exhibiting its manifestation, though it could possibly exhibit its manifestation at some other time. For example, while the switch is off, the power of the light bulb to illuminate is dormant, not manifesting; when the switch is turned on, the bulb lights up, its power to illuminate is active and manifest. (McKitrick, 2013, p. 127) ${ }^{15}$

McKitrick assumes that the assumption that dispositional properties can be instantiated without being manifest is essential for dispositionalism. Usually, the manifestation of a disposition is understood to require boundary conditions and a trigger. In dispositional monism, all these factors are attributed to powers, so that the manifestation of a disposition consists of something gaining a power. However, this does not mean that this power is manifest. In other words, something else must be added in order to distinguish the acquisition of a latent power from the acquisition of a manifest power. And the powers that bring about manifestation-McKitrick focuses on the trigger-must be understood as active powers in order to enable the acquisition of a new power:

This suggests that, if $\mathrm{A}$ is the triggering power and $\mathrm{B}$ is the target power, merely acquiring power $\mathrm{A}$ is not sufficient for activating power B: Power A must be manifest. (McKitrick, 2013, p. 127)

If dispositional monism understands manifestation only as the acquisition of a new power, it is in danger of falling into regress: Assuming that the powers are activated by something acquiring a power, then this is also true for the triggering power. Something has to acquire a power in order for the trigger power to be activated. But in order for the power B that activates trigger A to be activated, something must acquire another power $\mathrm{C}$. For $\mathrm{C}$ to be activated, something must acquire another power D, and so on. (McKitrick, 2013, p. 129).

McKitrick discusses different ways to stop the regress; the most promising candidate is the assumption that powers are always acting, even when they are not manifest (always acting view). This is the view of Mumford and Anjum (2011). According to this view, the difference between the passive and active state of a power does

$\overline{15}$ Also in her 2018, p. 104f., p. 128. 
not exist; rather, powers are active at all times. This is not a potential objection to DMI, since it does not differentiate between passivity and activity but between latency and manifestation. DMI does not maintain that being latent is equivalent to not being active i.e. passive and being manifest is equivalent to being active. Being active and manifesting are different things. A power can be active and yet not become manifest because another power prevents it from manifesting. So, it is possible to say that a power is active, but latent nonetheless. Hence this account is compatible with an always acting view as well as other views concerning this issue.

However, even if dispositions are taken to be always acting, it seems important that the difference between non-manifest and manifest disposition or power is preserved. This could be understood as follows: the non-manifest but active power is like a rotating cogwheel that does not do any work because it is not connected to another cogwheel. The manifestation of the power comes about when the power interacts with other powers according to the mutual manifestation partner theory. In the model of the cogwheel, the power manifests itself in the same way that a rotating cogwheel moves another cogwheel by being connected to it in a suitable way. An example of such a power is electric charge. An electrically charged body generates an electromagnetic field even if no other electrically charged specimen is in this field and no interaction of charges takes place. The manifestation of a power is therefore not connected with a change of state, but with a change of location. Although this actually stops the regress of the activation of powers discussed by McKitrick, the approach also leads to open questions: The idea that it makes no difference for the power itself whether it is manifesting or not seems implausible. After all, natural modality is not explained or grounded in this way. ${ }^{16}$ To the contrary, the powers only perform work in the case of interaction, i.e. manifestation. All this suggests that it makes a difference for a power whether it is not manifesting or whether it is manifesting itself. For DMI it is irrelevant whether the latent power is considered active or not.

\subsection{DMI and partial identity}

DMI thus assumes the following: There is some form of identity between latent dispositions and their manifestations. More clearly stated:

(DMI) $\mathrm{P}_{1}$ and $\mathrm{P}_{\mathrm{m}}$ are the very same property $\mathrm{P}$, but $\mathrm{P}_{1}$ and $\mathrm{P}_{\mathrm{m}}$ are in different modes.

In other words: Dispositions manifest themselves. Dispositions are numerically identical with their specific manifestations. It is exactly that property $\mathrm{P}$ which becomes manifest in the behaviour which is the specific manifestation of $\mathrm{P}$.

The assumption that a disposition is identical with its manifestation has the advantage over the separation thesis, that with it the necessity for a disposition to

\footnotetext{
${ }^{16}$ It is only consequential that Mumford/Anjum assume a primitive dispositional modality (Mumford \& Anjum, 2011, p. 175ff.).
} 
manifest itself in a certain property $\mathrm{P}$ is backed. Because if the disposition to $\mathrm{P}$ is at least partially identical with the manifest property $\mathrm{P}$ and if dispositions are conceived in such a way, that it is their nature, that they themselves are those, which are manifest in their manifestations, then $\mathrm{P}_{1}$ can only manifest in $\mathrm{P}_{\mathrm{m}}$. More precisely qualitative natural necessity is explained. That a disposition necessarily manifests itself in a certain property $\mathrm{P}_{\mathrm{m}}$, given its conditions of manifestation, but not in another numerically and qualitatively different property $\mathrm{G}_{\mathrm{m}}$ is explained by this.

The identity between $\mathrm{D}$ and $\mathrm{M}$ can of course not be strict identity but only a partial identity, since it is essential for dispositionalism to draw a distinction between a latent disposition and its manifestation in the sense that there may be dispositions that are never manifest (cf. Giannini, 2020). Furthermore, there must not be absolute identity between $\mathrm{D}$ and $\mathrm{M}$, because otherwise there would be a trivial, analytical relation of necessity between a disposition and its manifestation, and not the desired de re qualitative modality. There can only be partial identity between $\mathrm{P}_{1}$ and $\mathrm{P}_{\mathrm{m}}$ :

$$
\mathrm{P}_{1} \cong \mathrm{P}_{\mathrm{m}}
$$

So, DMI states the following theses:

(DMI-1) The disposition D is partially identical with its specific manifestation $\mathrm{M}$.

(DMI-2) A disposition is constituted by its property $\mathrm{P}$ and its mode of instantiation.

(DM-3) Dispositional properties can be instantiated in two different modes, a latent mode and a manifest mode, such that if some $\mathrm{x}$ instantiates $\mathrm{P}, \mathrm{P}$ can either be instantiated latently $\left(\mathrm{P}_{1}\right)$ or manifestly $\left(\mathrm{P}_{\mathrm{m}}\right)$.

(DMI-4) The manifestations of dispositions are contributions to outcome states of a complex system.

Partial identity in DMI-1 is to be understood similar to Armstrong's concept of partial identity with respect to the similarity in properties (Armstrong, 1997, p. 17f.; pp. 51-57). Here I take partial identity to be thus: ${ }^{17}$

$\mathrm{A}$ and $\mathrm{B}$ are partially identical, if.

- A has an element $X$ and

- B has an element Y,

- so that $\mathrm{X}$ and $\mathrm{Y}$ are strictly identical

and

- there is at least one element $\mathrm{Z}$

such that.

- $\mathrm{Z}$ is the element of $\mathrm{A}$, but not of $\mathrm{B}$

\footnotetext{
${ }^{17}$ Most accounts of partial identity are mereological but there are also non-mereological. I am content with mereological partial identity here.
} 
or

- $\mathrm{Z}$ the element of $\mathrm{B}$, but not of $\mathrm{A}$

DMI-2 takes dispositional properties to be complex entities, that have several constitutive features. ${ }^{18}$ Two features are essential for a property being a dispositional property: the property $\mathrm{P}$ confers its bearer with a quality, i.e. that it is a certain way. Also identity theories commonly attribute this feature to dispositional properties. ${ }^{19}$ Differing from these accounts however DMI takes it that qualitativity of a property is not a sub-feature of the property but that it is the property simpliciter. Also differing from identity theories DMI holds that dispositional properties can be instantiated or exemplified in two different modes, latent or manifest.

DMI-3: If properties are ways of being (Armstrong, 1997, pp. 30-31; pp. $123-124),{ }^{20}$ in the sense that if $\mathrm{x}$ has the property $\mathrm{P}$ then $\mathrm{P}$ is one way $\mathrm{x}$ is, then there can also be modes of $\mathrm{P}$ being one way $\mathrm{x}$ is. Latency and manifestation are modes of the way $\mathrm{x}$ is $\mathrm{P}$. It is a feature of the property although it concerns its instantiation or exemplification. ${ }^{21} \mathrm{I}$ assume this because if it would concern instantiation alone, i.e., if instantiation would come in two modes, then the nature of instantiation would decide that all properties are dispositional; this seems unpersuasive. I think the issue whether properties are dispositional or categorical, i.e. quiddistic, concerns the nature of properties.

So, concerning their qualitative feature $\mathrm{P}, \mathrm{D}$ and $\mathrm{M}$ are strictly identical, but concerning their mode of instantiation D and $\mathrm{M}$ come apart. Hence partial identity means that there is overlap with respect to $\mathrm{P}$ between $\mathrm{D}$ and $\mathrm{M}$, but not with respect to its mode of instantiation. ${ }^{22}$ What is also important to notice is that this kind of overlap means that there is also numerical identity between this instantiation of $\mathrm{P}$ when it is instantiated latently and when it is instantiated manifestly. In this respect it is a certain property instance which manifests itself.

It seems less difficult to explain what it means to instantiate a property manifestly. This seems very much to be what we commonly think when we assume that some object instantiates a property. In DMI the manifestation is a contribution hence it is a force exerted on something resulting in some behaviour of a system, the outcome

\footnotetext{
18 Most dispositionalist accounts of properties take properties to be complex entities. Bird's powers have potencies and essences, identity theories have qualitative and dispositional features.

19 Jacobs (2011), Tugby (2012, 2013), Gianotti (2019).

20 That it is particularly this feature of properties that matters for the problem I am dealing with is also seen by Livanios (2020).

21 I want to be neutral about which theory of properties to adopt. There are very many options on the market: Tugby argues explicitly for a Platonic realism about universals (Tugby, 2013); and Bird also seems to prefer it, although he leaves open the question of which of the two conceptions fits better with dispositionalism and believes that his theory is compatible with both variants (Bird, 2007, p. 12; pp. 51-55). Molnar holds a trope theory (Molnar, 2003) and Whittle even nominalism (Whittle, 2009). Therefore I want to be neutral about which connection there is between a property and the particular that has it. However, if it turns out that the DMI account is only compatible with one account of properties, I would be willing to accept it as long as it is respectable.

22 To spell out partial identity by overlap is a common move taken by Armstrong (1997) as well as by Lewis $(1991,1993)$.
} 
state. But what does it mean to instantiate a property latently? The basic idea is that it is the very same property understood as a quality, which makes the object that has it be in a very certain way that allows it to make a contribution to some outcome state; however, the object that has it is not doing any work involving this quality or property. Being latently instantiated means that a power is instantiated and it might also be active-as taken by the always acting-view-however, it is not doing any work. It sits there with its particular or at its space-time region "ready to go", as Martin famously puts it, or waiting to get manifested. If we combine DMI with Tugby's QDE scheme, we can say that the qualitativity of a property $\mathrm{P}$ is such that $\mathrm{x}$ is in a certain way when $\mathrm{x}$ instantiates $\mathrm{P}$, and this way can either be latent or manifest. Thereby $\mathrm{x}$ can be in a latent state or in a manifest state regarding its being $\mathrm{P}$. In both states $\mathrm{x}$ instantiates $\mathrm{P}$ but in different modes.

'Being latently instantiated' also differs from 'being possibly instantiated', ${ }^{23}$ although it makes modal assertions true in the common way such that if $\mathrm{x}$ instantiates $\mathrm{P}$ latently then it is possible that $\mathrm{x}$ manifests $\mathrm{P}$. By manifesting $\mathrm{P} \mathrm{x}$ does not acquire a new property it—so to speak — shows off the property $\mathrm{P}$ it already had.

But what kind of thing are states or modes of a property's instantiation? A very easy model would be to think of involving a second order property, the property of 'being in a manifest state', lets call it MS. MS is instantiated or exemplified by the dispositional property $\mathrm{P}$ once one set of dispositional properties is present that gives rise to the outcome state related to this set of contributions. The instantiation of MS is dependent on the compresence of other suitable dispositional properties. The latent state would be defined by instantiating P but not the second order property MP. The manifestation of a dispositional property would then after all consist in the acquisition of a new property; however unlike according to the standard accounts it is not the manifestation that is acquired but the state property of 'being in a manifest state' which is a second order property of the disposition with its instantiation depending on the compresence of other correlated dispositional properties that are suitable to bring about some outcome state. ${ }^{24}$ The directedness of dispositions to their manifestations has its basis in this identity structure guaranteeing for invariance; it comes as an ontological free-lunch in Armstrong's terms.

\footnotetext{
${ }^{23}$ I stress this aspect to demarcate DMI against certain readings of Aristotelian actualism in which Aristotle holds that what exists is only the actual and that potentialities are not actual hence they do not exist. Being latently instantiated means that the property is actually instantiated.

24 There is a possibility to model this along the lines of a triggering model of manifestation; in this case the second order property would be 'being latently instantiated'; the manifestation of the disposition would consist in the loss of this property, the disposition would be unleashed so to say by its contribution-partners. This model however is more prone to objections I suppose. A first objection is that manifestation is commonly seen as involving property acquisition not its loss.
} 
According to DMI-4, DMI should be coupled with a contribution theory of manifestation. ${ }^{25}$ Since dispositions are not essentially linked to other properties in it, unlike in essentialist versions of the standard model, nomological correlations between properties would otherwise not be included in this model. Thus, as in the contribution theory, DMI should assume that dispositions manifest themselves in their contributions to outcome states, their contributions being the same in all possible constellations of interacting dispositions. Hence, this account also differs from the standard-model in identifying what kind of entity the manifestation of a disposition is. According to this model the contributions together bring about an outcome state. In the standard model the outcome state is the manifestation of the disposition. However, in DMI the manifestation of a disposition is the contribution, or influence in Corry's terms.

Besides being simple what is positive with this option is first that the manifestation of a disposition involves a change of state after all. A second virtue is that metaphysically speaking what happens to the first-order dispositional property is very little by acquiring DS, its identity is not touched at all. A third virtue is that this model is comparatively neutral with respect to property theory and also with respect to more fine-grained analyses of different ways in which the manifestation of a disposition comes about. The notion of second-order property covers a range of different metaphysical models of how a manifestation might come about or what it consists in. This also leaves room for different ways this structure can be exemplified or instantiated, there may be dispositions that are always manifesting because they are always in suitable circumstances or dispositions that are always acting or dispositions that are activated by some condition.

It is a question of its own how the contributions bring about the outcome state. Martin has come up with the idea in terms of dispositions as mutual manifestation partners. According to him it is just their coming together which brings about the outcome state-in his model the manifestation:

You should not think of disposition partners jointly causing the manifestation. Instead, the coming together of the disposition partners is the mutual manifestation: the partnering and the manifestation are identical. (Martin, 2008, p. 51).

\footnotetext{
25 This account has first been suggested by Shoemaker (1980), its most detailed version has been elaborated by Corry (2019). Corry however terms his contributions "influences" and there are significant differences between the original account by Shoemaker and Corry's. In contrast to the DM identity theory Corry thinks that there is a difference between dispositions and his influences which is more than in partial identity (Corry 2019, p. 33). However, he seems to be motivated by very similar concerns: "These influences are distinct from the powers themselves, since an object can have a power even when that power is not manifested (and so exerts no influence)." (Corry 2019, p. 33) But contrary to DMI Corry thinks that there are two kinds of modalities built into both, the powers and their influences. It is also a distinguishing mark between them that they are different: "Because powers and influences are characterized by different modalities they must be different things." (Corry 2019, p. 51). Nevertheless, it is a very central concern of Corry's account that his powers and influences ground invariance (20-35). In this respect DMI takes it that the invariance is built into the structure of dispositional properties and that this invariance grounds the natural modalities that dispositions are supposed to ground and explain.
} 
Probably, this is best understood as spatiotemporal combination. Along these lines the manifestation of a disposition should according to DMI be taken to come about by a spatiotemporal combination of several contributions resulting in an outcome state. The manifestation process is hence neither a transition from potency to act nor an activation of a power it is just a putting the power to work by putting them together. In a next step I want to sketch how in this account dispositions might ground natural modalities, the concern that is central to this model.

\subsection{The grounding of natural modality according to DMI}

Corry has very nicely pointed out which theoretical work can be done by his influences, which are most similar to contributions: the most important thing is that they are invariant in all possible circumstances of manifestations. He shows that this invariance of influence is presupposed in reductive explanations (Corry, 2019, pp. 32-35). However, in Corry's account the invariance is postulated like in Bird's account the SR-relation between certain properties. I reckon it a special feature of the DMI-model that it covers this invariance. The contributions of dispositional properties are invariant in all possible constellations of powers. Because it is the very same quality which manifests itself, a dispositional property's contribution is invariant under all conditions. As a result in all instances of the same type of dispositions the very same contributions are made. ${ }^{26}$ Hence the inference problem that plagues Bird's account of laws of nature cannot occur.

This is not to say that the outcome state is invariant under all conditions; to the contrary, it varies with respect to the other contributions involved. This is a desirable feature as Corry has persuasively pointed out in detail because e.g. in the ideal gas law we not only want to know which outcome states relate to the contributions involved under idealized conditions but also with some additional laws how a system behaves under less than ideal conditions, i.e. what influences the other contributions make. ${ }^{27}$

Hence, this invariance can figure as the metaphysical basis of that invariance which characterizes, according to some philosophers of science, natural necessity in laws of nature. ${ }^{28}$ Hüttemann has pointed out that although invariance itself is

\footnotetext{
${ }^{26}$ Of course, in a complete picture of the approach, more should be said about how it fits with a theory of universals or a theory of tropes or a form of nominalism at this point. This is not special for a dispositionalist account of laws but the same for all.

27 Cf. also Hüttemann (1998).

28 "A law statement may be said to be naturally or physically necessary if it is invariant under a change of initial conditions." (Mittelstaedt \& Weingartner, 2005, p. 226). Woodward argues that invariance is the feature which is important for understanding the notion of lawlikeness and that dispositions are the entities to ground it: "[...] an account of laws which relies on notions like invariance and stability seems to fit naturally with the idea briefly adumbrated above, that laws are abstract (and often highly idealized) descriptions of capacities and dispositions characteristic of particular objects or systems, " (Woodward, 1992, p. 205). Since law statements typically describe the-often mathematical-correlation between two or more variables standing in for properties of a system we can say that if the contribution of a property to an outcome state is invariant due to its identity, then the correlation of two or more contributions to outcome states will display invariant behaviour too. We may call this a rule of recombination invariance (cf. also Corry, 2019, p. 79f.).
} 
a modal notion there is yet progress in reducing nomological necessity to invariance because it makes modality empirically accessible (Hüttemann, 2021, p. 27, pp. 33-40). DMI is supposed to ground this invariance. ${ }^{29}$

There might however be the worry that this move cannot account for the laws' necessity after all, because it brings in the structure of the standard model yet again with its problem of a stipulated necessary connection between disposition and manifestation, yet transformed to the relation between the contributions and the outcome state. Probably most laws deal with correlations between different variables at least some of which-according to dispositionalism—stand in for powers. Is it by stipulation that, say, the contributions F, G, H necessitate the outcome state I but not the outcome state $\mathrm{J}$ ? A short and preliminary answer to this worry would be that the invariance that follows from the identity structure between dispositions and their manifestations transgresses to the level of mutual manifesting contributions and outcome states. This transgression could be motivated by the view that the contributions are parts of the outcome states and there is also partial identity between the contributions and the outcome states. However, since there commonly are multiple contributions bringing about the outcome state there is no qualitative and numerical identity between a disposition and the outcome states it is related to. DMI can hence assume a kind of "power flow" from dispositions to outcome states and hence assume invariance across these stages as well.

This new conception of the manifestation of a disposition could give rise to the following objection: The manifestations of dispositions are usually accompanied by change. Change, however, is a change of characteristics. When a disposition manifests itself, there is usually a change of properties of the object or system. The DMI theorist can counter this objection by referring to the distinction between a metaphysical deep structure of particulars instantiating properties in space-time from the surface structure of events supervening on that level. A change of state of the dispositions itself is already a metaphysically relevant change, and furthermore a change of state is often associated with a change of properties on the surface structure of events. In this respect, DMI works exactly like the contribution theory. It does not rule out that the joint causing of an event by the contributions of several dispositions is bound up with the fact that objects acquire new properties; rather, this is precisely its model.

All accounts of dispositions have to deal with the question whether dispositional properties should be seen as determinable or determinate properties and whether they are single-track or multi-track. In this respect the DMI account can make the very same move as Corry and accept that a dispositional property can be multi-track concerning its contributions. Yet, as Corry points out, this does not undermine the invariance it is supposed to ground since the invariance is only bound up to determinate situations (Corry, 2019, pp. 55-58). ${ }^{30}$

\footnotetext{
${ }^{29}$ Hüttemann also assumes that invariance is tied to dispositions, but does not want to ground it on them (Hüttemann, 2021, pp. 73-79).

${ }^{30}$ Hüttemann also assumes that dispositions are or can be multi-track so that they can explain laws of nature (Hüttemann, 2021, p. 50f.).
} 


\subsection{The structure of dispositional properties according to DMI: an example}

Finally, I would like to illustrate the approach with an example: the dispositional property of electric charge. Having electric charge is a dispositional property because it is a property that is manifest under certain conditions only and gives rise to various behaviours in certain conditions one of which is described by the equation (Coulomb law): $\mathrm{F}=\kappa_{\mathrm{e}} \mathrm{q} / \mathrm{r}^{2}{ }^{31}$ The associated law would say:

Electrically charged particles behave according to the equation $F=\kappa_{\mathrm{e}} \mathrm{q}_{1} \mathrm{q}_{2} / \mathrm{r}^{2}$. Here, $\kappa_{\mathrm{e}}$ is the Coulomb-constant while $\mathrm{q}_{1}$ and $\mathrm{q}_{2}$ are the two charges and $\mathrm{r}$ the distance between the two charged particles. According to DMI the behaviour that is described by Coulomb law is the outcome state of the system of two charged particles. Each particle contributes to this behaviour in manifesting its dispositional property of electric charge. If the manifestation conditions are not fulfilled, i.e. the two particles are not in appropriate vicinity to each other, the properties are latent.

Manifest mode: $\mathrm{E}_{\mathrm{m}} \mathrm{x}:=\mathrm{x}$ repels equally charged particles and attracts complementarily charged ones.

Latent mode: $\mathrm{E}_{1} \mathrm{x}:=\mathrm{x}$ latently repels equally charged particles and attracts complementarily charged ones.

Once the manifestation conditions are fulfilled the E-property of both particles instantiate the second-order property of "being manifest". Now, what is the exclusive explicative strength of DMI is that it is the disposition itself that brings about the outcome state. There is no intermediate entity which has to be tied to the disposition and stipulatively necessitate the outcome state. It is by instantiating $\mathrm{E}$ that some particle $\mathrm{x}$ behaves according to Coulomb's law. The manifestation of its power property comes about by the coming together of another particle at a certain distance. ${ }^{32}$ By entering appropriate conditions the property of electric charge acquires the second-order property of "being manifest". In this mode of instantiation, it brings about the outcome state, a change of speed and direction of motion of the particles. And it does so in an invariant way because it is the very same property that does it.

The answer to the four problems of the standard model through DM identity theory is: In DM identity theory, directedness is not a relation between numerically distinct properties. The directedness relation between $P_{1}$ and $P_{m}$ is a non-mereological whole. This should be conceptualized along the lines of the instantiation of properties in facts in Armstrong (1997, pp. 118-119). Directedness is not a constitutive element of $\left(\mathrm{P}_{1}, \mathrm{P}_{\mathrm{m}}\right)$ but the form of the whole. The fundamental structure of dispositions is therefore $\left(\mathrm{P}_{\mathrm{l}}, \mathrm{P}_{\mathrm{m}}\right)$. The manifestation of a disposition as a process thus consists in the change from one state of the object according to its being $\mathrm{P}$ to the other. ${ }^{33}$

\footnotetext{
31 My discussion of this case is very much along the lines of Corry (2019, p. 56). It translates this case to the DMI-model also by filling in some detail along the lines of Hüttemann (2021).

32 According to Corry the distance itself is also a contribution (Corry, 2019, p. 56). I think this is an important move to make clear: the contributions of the particles depend in their determinate values on the value of $r$.

33 In this way it is very possible that the particular loses its disposition as an end-result of the manifestation process or even seizes to exist itself.
} 
Another advantage of the DMI is that it allows the correct natural modalities of the laws of nature to emerge in the right places: If $\mathrm{x}$ instantiates $\mathrm{P}_{1}$, then in the strict sense it is necessary that $\mathrm{x}$ manifests $\mathrm{P}$ given its manifestation conditions. The outcome is qualitative natural modality. The qualitative natural modality is a result of the identity between $\mathrm{P}_{1}$ and $\mathrm{P}_{\mathrm{m}}$. Since there is strict identity concerning the quality of the property there is strict identity in the quality which is brought about in a manifestation of a power. The qualitative identity between a disposition and its manifestation models the metaphysical grounding of Corry's invariant behaviour under all possible conditions of manifestation. The manifestation event is also conditionally necessary depending on the occurrence of the manifestation conditions. A latent disposition makes a specific behaviour necessary if the manifestation conditions are given.

\section{Conclusions}

As sketched above DMI has three important advantages over the standard model: first that there is no factuality of the connection between a disposition and its manifestation, but identity and second, that this identity grounds the natural modality of laws of nature via invariance. Third, the model of the structure of dispositional properties according to DMI is simpler than the models of identity theories and quite elegantly captures intuitions that motivate dispositional accounts in general.

Yet, there are many details still to be worked out: The following parts seem the trickiest: (i) the role of determinable and determinate in this account and (ii) the precise version of multi-tracking with respect to the contributions that the manifestations make and (iii) the argument that invariance is transferred from the disposition's manifestation to its jointly bringing about the outcome state. Because there are accounts on the market that have shown that this can successfully be done the prospects are not too dim (e.g. Corry, 2019). It would be the subject of further research to put together and elaborate all the parts and details of the approach if the model as such proves worthwhile.

Acknowledgements I kindly thank two anonymous reviewers for their constructive and helpful comments, Andreas Hüttemann for having supported my work, Sascha Settegast, Robert Mersiowsky and David Hommen for giving me valuable feedback on a former draft of the paper and Deutsche Forschungsgemeinschaft for funding this project at an earlier stage.

Open Access This article is licensed under a Creative Commons Attribution 4.0 International License, which permits use, sharing, adaptation, distribution and reproduction in any medium or format, as long as you give appropriate credit to the original author(s) and the source, provide a link to the Creative Commons licence, and indicate if changes were made. The images or other third party material in this article are included in the article's Creative Commons licence, unless indicated otherwise in a credit line to the material. If material is not included in the article's Creative Commons licence and your intended use is not permitted by statutory regulation or exceeds the permitted use, you will need to obtain permission directly from the copyright holder. To view a copy of this licence, visit http://creativecommons.org/licen ses/by/4.0/. 


\section{References}

Armstrong, D. M. (1997). A world of states of affairs. Cambridge University Press.

Barker, S. (2009). Dispositional monism, relational constitution and quiddities. Analysis, 69(2), 242-250.

Barker, S., \& Smart, B. (2012). The ultimate argument against dispositionalist accounts of laws. Analysis, 72(4), 714-722.

Bird, A. (2006). The regress of pure powers? Philosophical Quarterly, 57, 513-534.

Bird, A. (2007). Nature's metaphysics. Oxford University Press.

Bird, A. (2011). Monistic dispositional essentialism. In A. Bird, B. Ellis, \& H. Sankey (Eds.), Properties, powers and structures: Issues in the metaphysics of realism (pp. 35-41). Routledge.

Bauer, W. A. (2010). The ontology of pure dispositions. Dissertation University of Nebraska. (http://digit alcommons.unl.edu/philosophydiss/3)

Corry, R. (2019). Power and influence. Oxford University Press.

Engelhard, K. (2010). Categories and the ontology of powers: A vindication of the identity theory of properties. In A. Marmodoro (Ed.), The metaphysics of powers: Their grounding and their manifestations (pp. 41-57). Routledge.

Giannini, G. (2020). New powers for dispositionalism. In Synthese.

Giannotti, J. (2019). The identity theory of powers revised. In Erkenntnis, https://doi.org/10.1007/ s10670-019-00122-5.

Heil, J. (2012). The universe as we find it. Oxford University Press.

Heil, J. (2016). Causal relations. In A. Marmodoro \& D. Yates (Eds.), The metaphysics of relations (pp. 127-137). Oxford University Press.

Hüttemann, A. (1998). Laws and dispositions. Philosophy of Science, 65(1), 121-135.

Hüttemann, A. (2021). A minimal metaphysics for scientific practice. Cambridge University Press.

Ingthorsson, R. D. (2013). Properties: Qualities, powers, or both? Dialectica, 67(1), 55-80.

Ingthorsson, R. D. (2015). The regress of pure powers revisited. European Journal of Philosophy, 23(3), $529-541$.

Jaag, S. (2014). Dispositional essentialism and the grounding of natural modality. In Philosophers Imprint, 14(34).

Jacobs, J. (2011). Powerful qualitites not pure powers. The Monist, 94(1), 81-102.

Lewis, D. (1991). Parts of Classes. Basil Blackwell.

Lewis, D. (1993). Many but almost one. In J. Bacon et al., (Eds.), Ontology, Causality and Mind: Essays on the Philosophy of D. M. Armstrong (pp. 23-38). Cambridge University Press.

Livanios, V. (2017). Science in metaphysics: Exploring the metaphysics of properties and laws. Springer.

Livanios, V. (2020). Dispositional monism and the ontological distinction between unmanifested and manifested powers. In Ratio

Marmodoro, A. (2010). Do powers need powers to make them powerful: From pandispositionalism to aristotle. In History of Philosophy Quarterly, S. 337-352.

Marmodoro, A. (2014). Aristotle on perceiving objects. Oxford University Press.

Martin, C. B. (2008). The mind in nature. Oxford University Press.

Martin, C. B., \& Heil, J. (1999). The Ontological turn. Midwest Studies in Philosophy, 23(1), 34-60.

McKitrick, J. (2013). How to activate a power. In S. Mumford \& M. Tugby (Eds.), Metaphysics and science (pp. 123-137). Oxford University Press.

Mittelstaedt, P., \& Weingartner, P. (2005). Laws of nature. Springer.

Molnar, G., \& Mumford, S. (2003). Powers: A Study in Metaphysics. Oxford University Press.

Mumford, S. (2004). Laws in nature. Routledge.

Mumford, S. (2009a). Passing powers around. The Monist, 92(1), 94-111.

Mumford, S. (2009b). Causal powers and capacities. In H. Beebee, Ch. Hitchcock, \& P. Menzies (Eds.), The Oxford handbook of causation (pp. 265-278). Oxford University Press.

Mumford, S., \& Anjum, R. L. (2011). Getting causes from powers. Oxford University Press.

Psillos, S. (2006). What do powers do when they are not manifested? Philosophy and Phenomenological Research, 72(1), 137-156.

Shoemaker, S. (1980). Causality and properties. In P. van Inwagen (Ed.), Time and Cause (pp. 109-135). Reidel.

Taylor, H. (2018). Powerful qualities and pure powers. Philosophical Studies, 175(6), 1423-1440.

Taylor, H. (2019). Powerful problems for powerful qualities. In Erkenntnis. 
Tugby, M. (2012). Rescuing dispositionalism from the ultimate problem: Reply to barker and smart. Analysis, 72(4), 723-731.

Tugby, M. (2013). Platonic dispositionalism. Mind, 122, 451-480.

Woodward, J. (1992). Realism about laws. Erkenntnis, 36(2), 181-218.

Yates, D. (2016). Is Powerful Causation an Internal Relation. In A. Marmodoro \& D. Yates (Eds.), The Metaphysics of Relations (pp. 138-156). Oxford University Press.

Vetter, B. (2016). Counterpossibles (not only) for dispositionalists. Philosophical Studies, 173(10), 2681-2700

Whittle, A. (2009). Causal nominalism. In T. Handfield (Ed.), Dispositions and causes (pp. 242-285). Oxford University Press.

Publisher's Note Springer Nature remains neutral with regard to jurisdictional claims in published maps and institutional affiliations. 